\title{
OAIAA
}

The World's Forum for Aerospoce Leadership

\section{An Analysis and Review of Measures and Relationships in Space Transportation Affordability}

Edgar Zapata, Carey McCleskey NASA Kennedy Space Center

AIAA Joint Propulsion Conference, July 28-30 2104, Cleveland OH 
An Analysis and Review of Measures and Relationships in

Space Transportation Affordability

- Affordability, Prices and Costs

- Poor data, \$/kg, \$ per flight, and many, many caveats

- Productivity, Flight Rate and Yearly Capability

- Flights, tonnage

- Competitiveness

- Current vs. Growth

- Direct vs. Indirect Costs

- Where vs. Why, Comprising vs. Causing

- Closing 
An Analysis and Review of Measures and Relationships in Space Transportation Affordability

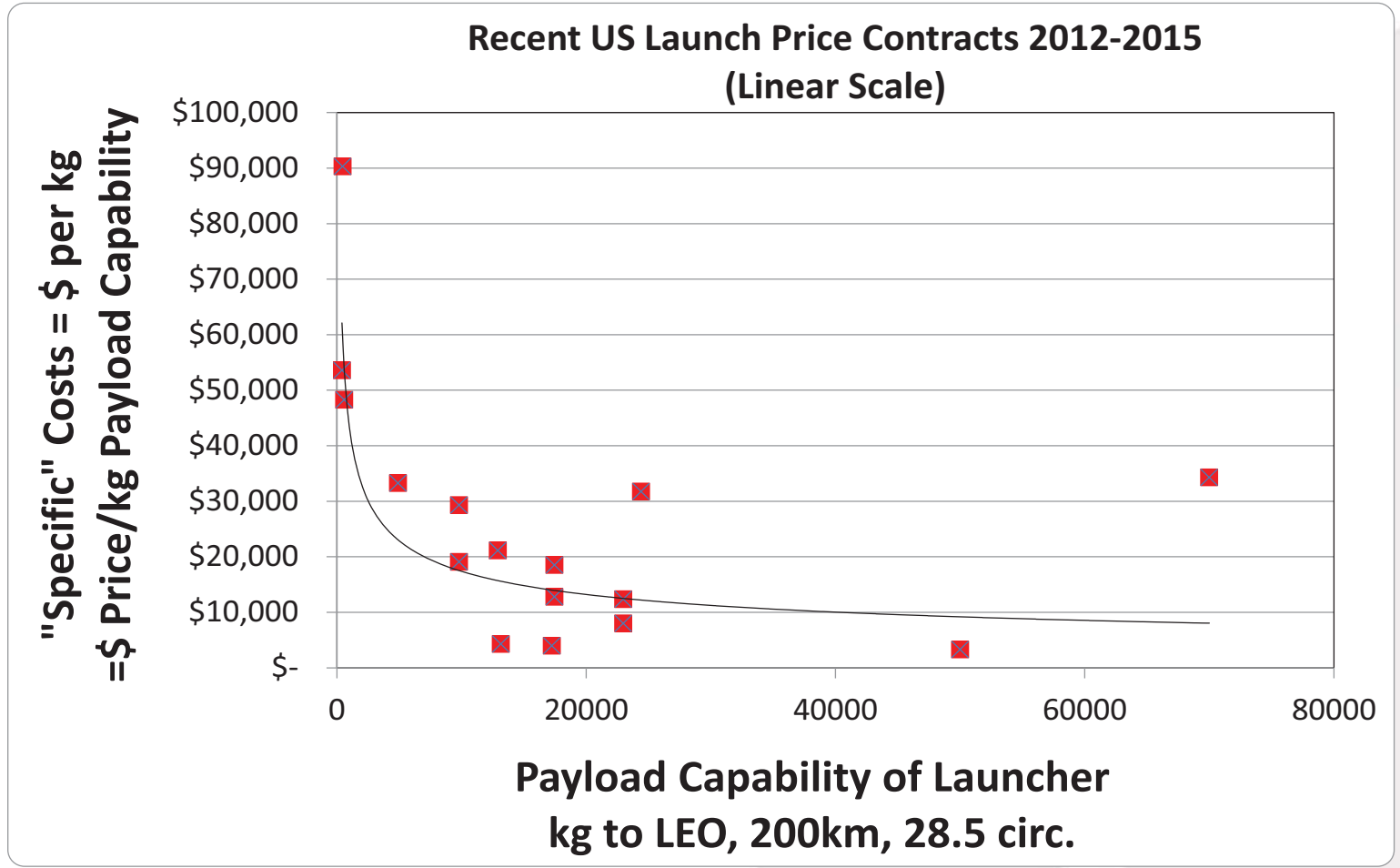

Figure 1: US Launchers and recent launch price contracts (2012-2015), using a linear scale and applying a power curve fit.

- A typical view of affordability

- Recent data used here

- Poor state of data, many contracts not public

- Causality (X to Y) not implied nor clear 
An Analysis and Review of Measures and Relationships in Space Transportation Affordability

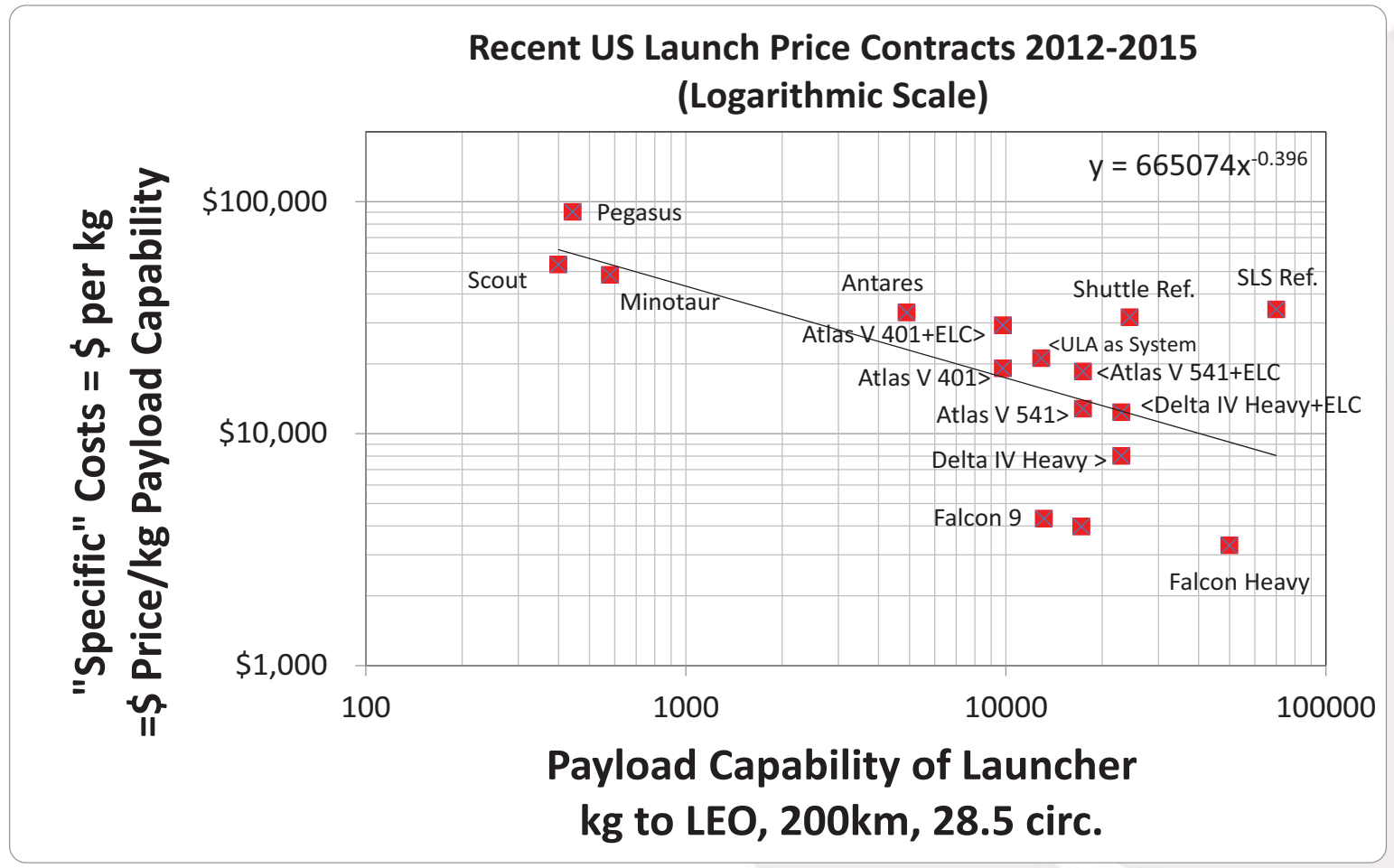

Figure 2: US Launchers and recent launch price contracts (2012-2015), using a logarithmic scale and applying a power curve fit.

- Shuttle only as reference (more ahead on apples/oranges)

- Poor state of data

- Similar to what an airline would have as CASM-cost per available seat mile

- Relative indicator of competitiveness 
An Analysis and Review of Measures and Relationships in Space Transportation Affordability

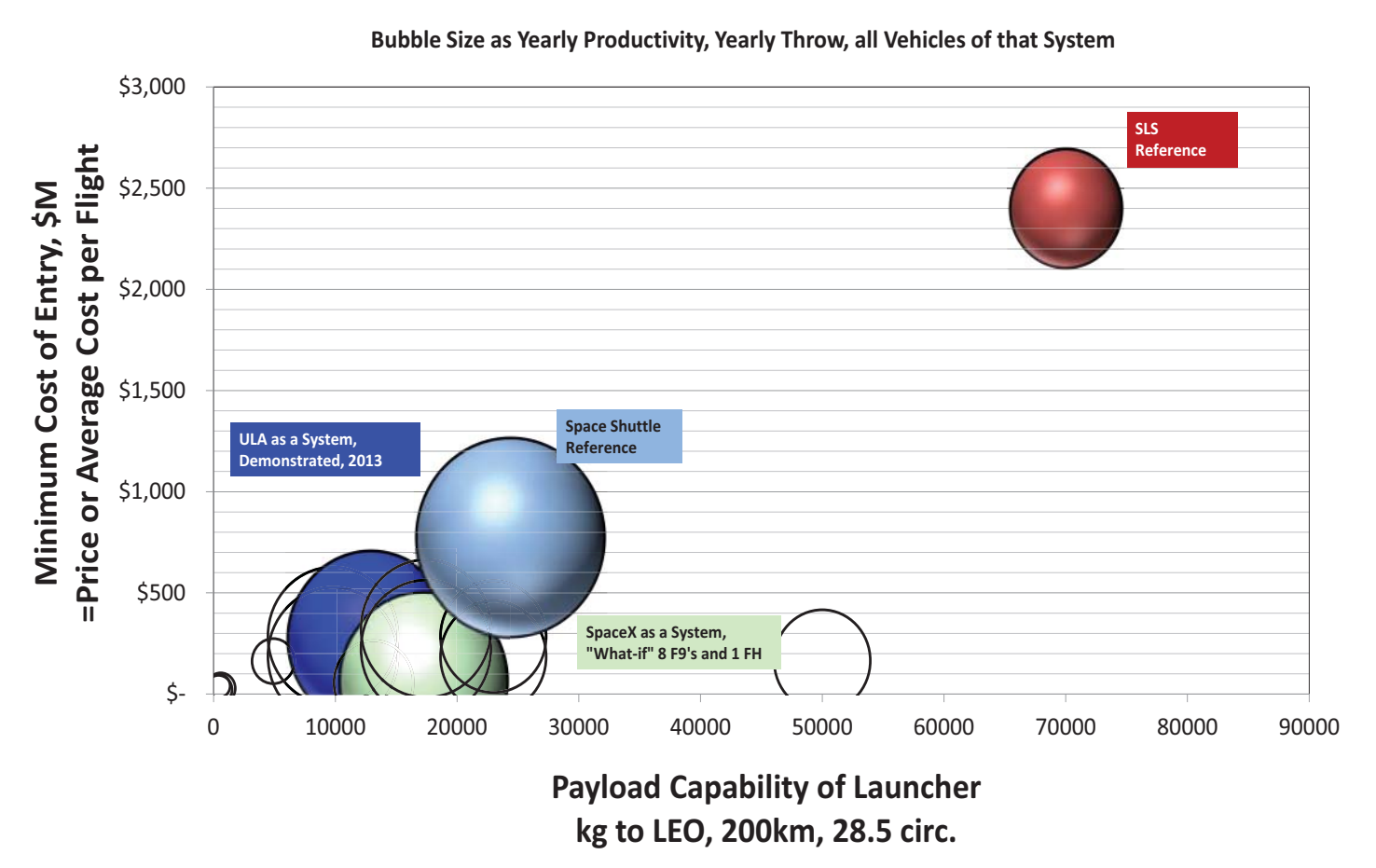

Figure 3: Using a bubble chart to show three variables; average payload capability of a system of launchers, the average cost of entry (or price to a customer), and the total tonnage capability deployed over a recent calendar year, as bubble size.

- Treat common capabilities as a system (all ULA, all SpaceX, etc.)

- Tonnage "capability" (not "actual"; more on this ahead)

- Want the bubble sizes to grow, and want more bubbles!

- US launchers only 
An Analysis and Review of Measures and Relationships in Space Transportation Affordability

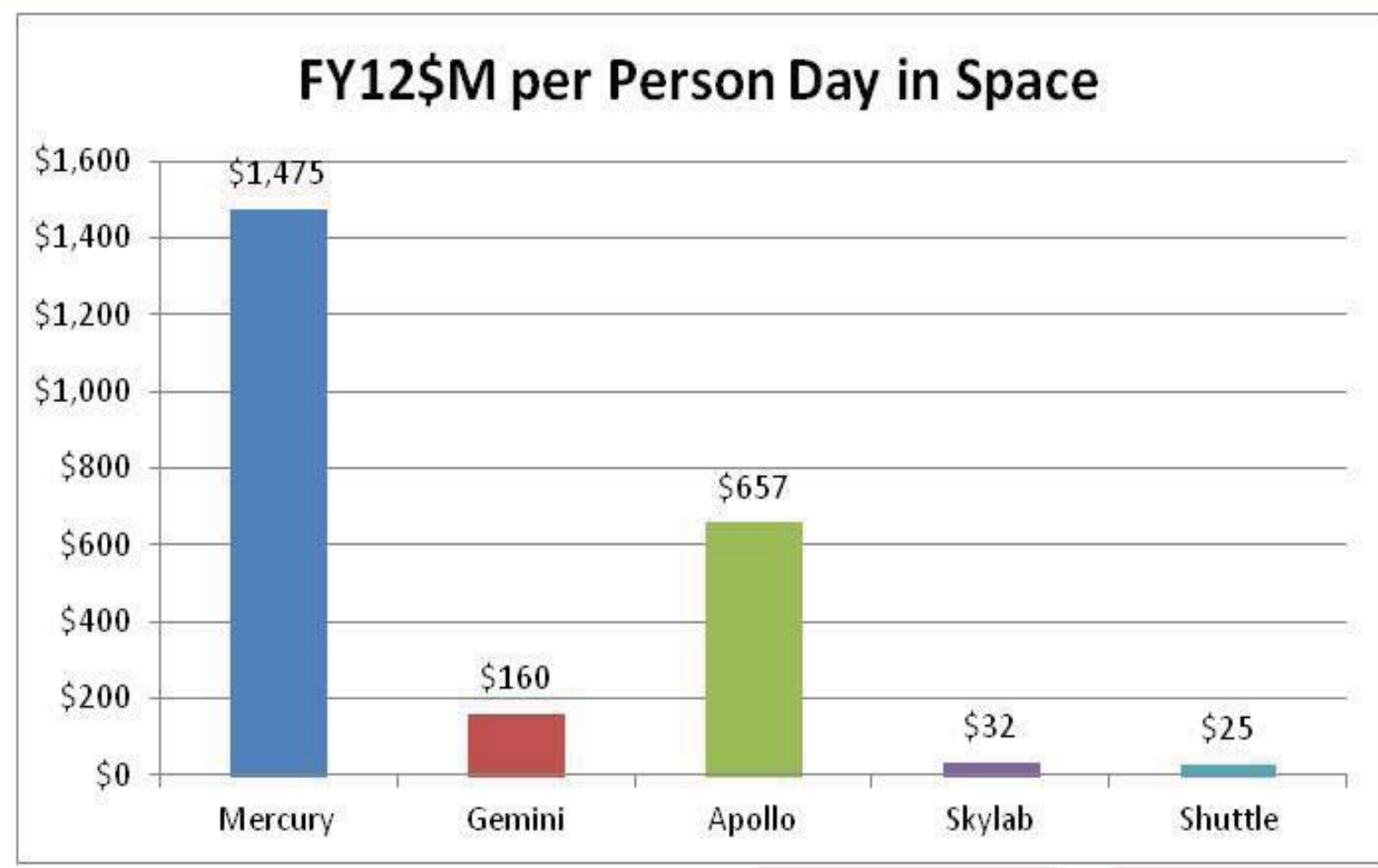

Figure 4: Courtesy Andy Prince, "Human Spaceflight Value Study, Was the Shuttle a Good Deal?" NASA Cost Symposium, 2012.

- On Shuttle: Measures of use to stakeholders go beyond cargo, kg, etc.

- Shuttle very "affordable" -by this measure and requirement, people to space

- Many affordability measures beyond \$/kg or price per flight

- Productivity, of some "value" 
An Analysis and Review of Measures and Relationships in Space Transportation Affordability

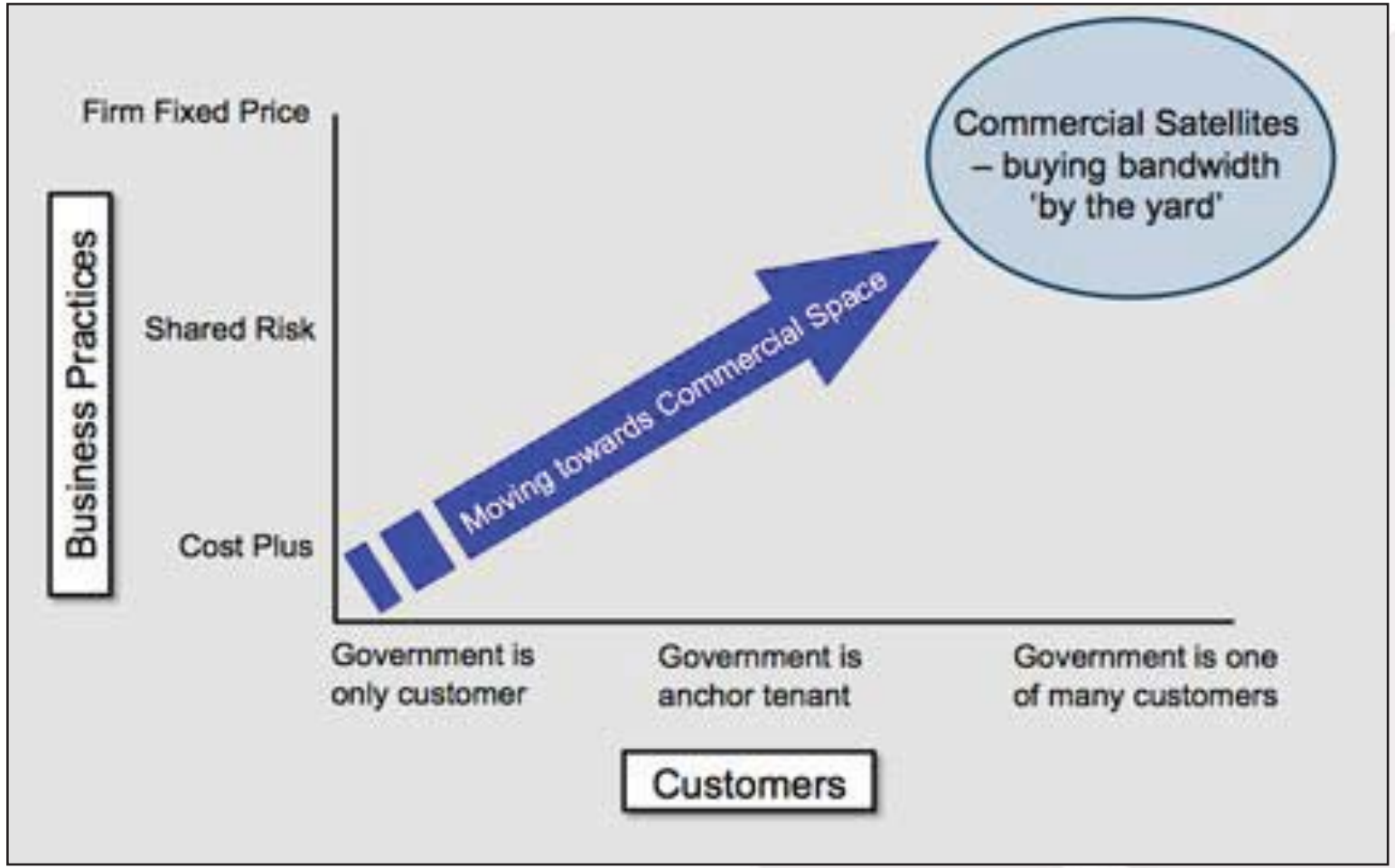

Figure 5: What is "commercial" space to NASA?

- Emerging / commercial space of great interest

- Visually, a spectrum of being more or less commercial

- Can compare two or more players as being more or less commercial

- Commercial is not about just being private sector; it's much more 
An Analysis and Review of Measures and Relationships in Space Transportation Affordability

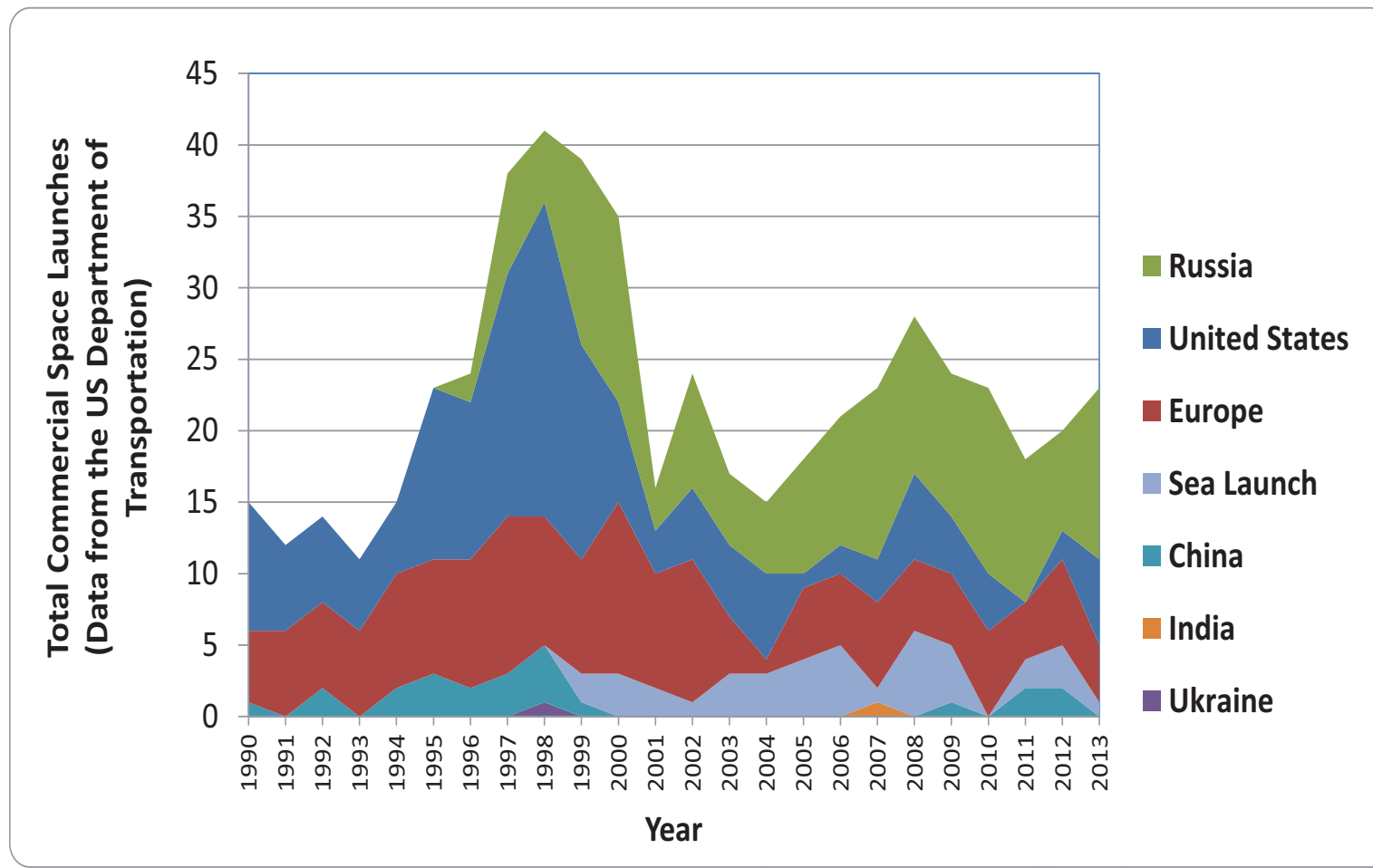

Figure 6: Graph created from raw data at the Department of Transportation for launches through 2012, plus 2013 data from the Federal Aviation Administration, "Commercial Space Transportation 2013 Year in Review,"

- Globally: Appear to be stagnant at about 20 commercial launches/year

- Definition is "competed" or "FAA licensed"

- 2013 - US appearing to see an uptick ? (but not the total market)

- What might cause market size to grow? Affordability + Productivity? 


\section{An Analysis and Review of Measures and Relationships in Space Transportation Affordability}

Table 1: Basic ingredients for a space exploration element (launch, spacecraft, habitat, etc.) being more commercial. The more these ingredients are captured, the more commercial the element is.

\begin{tabular}{|c|c|}
\hline Ingredient & Rationale \\
\hline $\begin{array}{l}\text { Product development } \\
\text { and use, amortizing } \\
\text { costs }\end{array}$ & $\begin{array}{l}\text { The business case depends on having non-government customers. The product } \\
\text { for the government is developed with non-government customers in mind. The } \\
\text { product or service is also provided to non-government customers. }\end{array}$ \\
\hline Contracts & The government uses firm fixed price type of contracts. \\
\hline Efficiency & $\begin{array}{l}\text { Provider applies mostly commercial best practices. These practices or "how" are } \\
\text { outputs. Capability, performance, safety, and cost goals are inputs. }\end{array}$ \\
\hline Incen & $\begin{array}{l}\text { Multiple suppliers (industry) and multiple buyers (government and non- } \\
\text { government) rationalize incentives, leading to success even when many } \\
\text { requirements (performance, safety, cost) appear at odds. No monopoly (single } \\
\text { provider) or monopsony (single buyer). }\end{array}$ \\
\hline \multicolumn{2}{|c|}{$\begin{array}{l}\text { ne formal, actual definition of what is "commercial" is expressed in the current space } \\
\text { olicy: "The term "commercial," for the purposes of this policy, refers to space goods, } \\
\text { orvices, or activities provided by private sector enterprises that bear a reasonable } \\
\text { ition of the investment risk and responsibility for the activity, operate in accordance } \\
\text { ith typal market-based incentives for controlling cost and optimizing return on } \\
\text { vestment, and have the legal capacity to offer these goods or services to existing or } \\
\text { tential nongovernmental customers." }\end{array}$} \\
\hline
\end{tabular}


An Analysis and Review of Measures and Relationships in Space Transportation Affordability

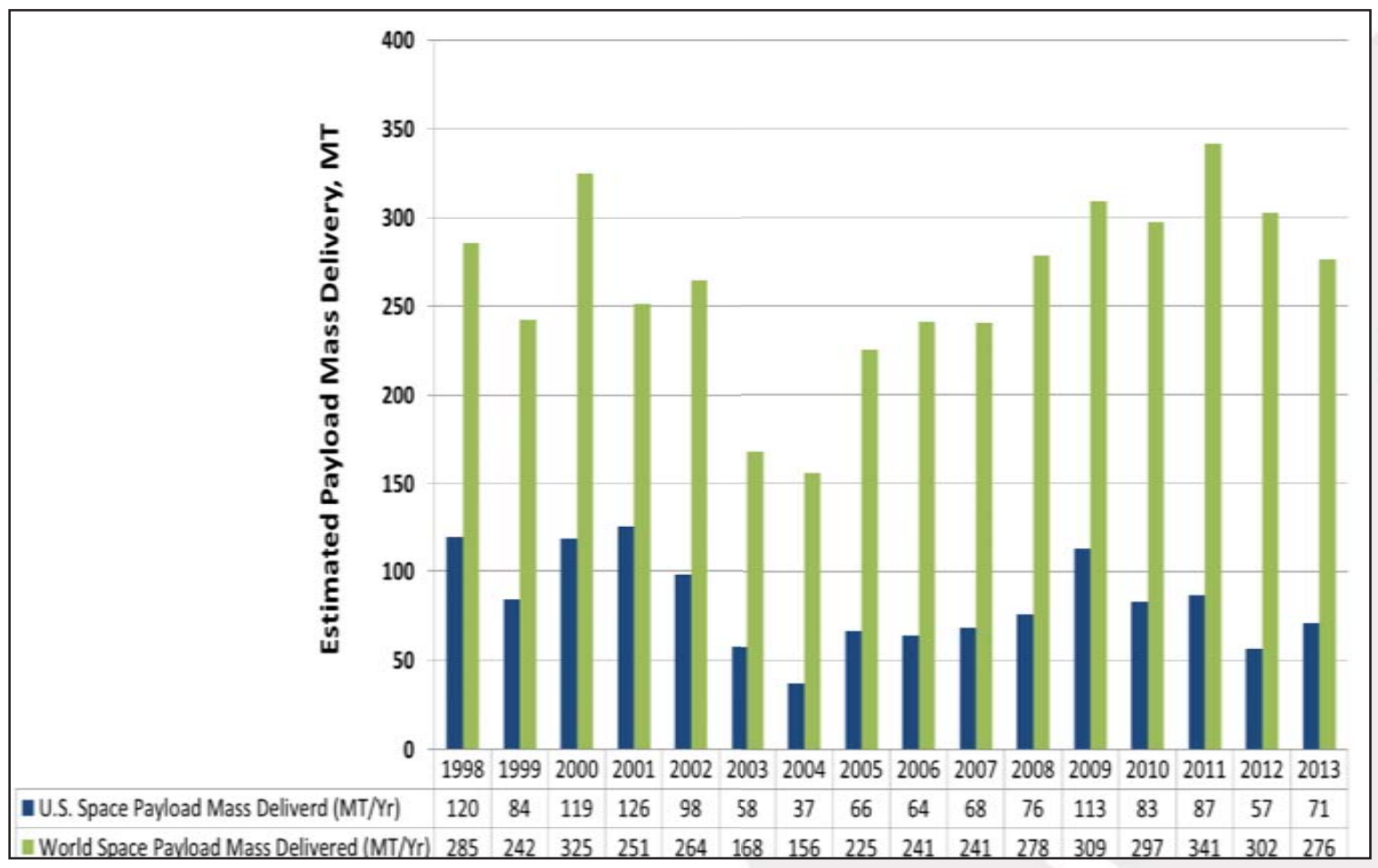

Figure 7: A view combining the launch record with estimated actual payload masses.

"Actual" tonnage being less than "capability" of launcher would mean far more $\$ / \mathrm{kg}$ and price per flight, in practice.

The data here has been compiled from two main sources:

(1) FAA Commercial Space Transportation, Year in Review reports

(2) Payload launch masses estimated from SpaceLaunchReport.com. 


\section{An Analysis and Review of Measures and Relationships in}

Space Transportation Affordability

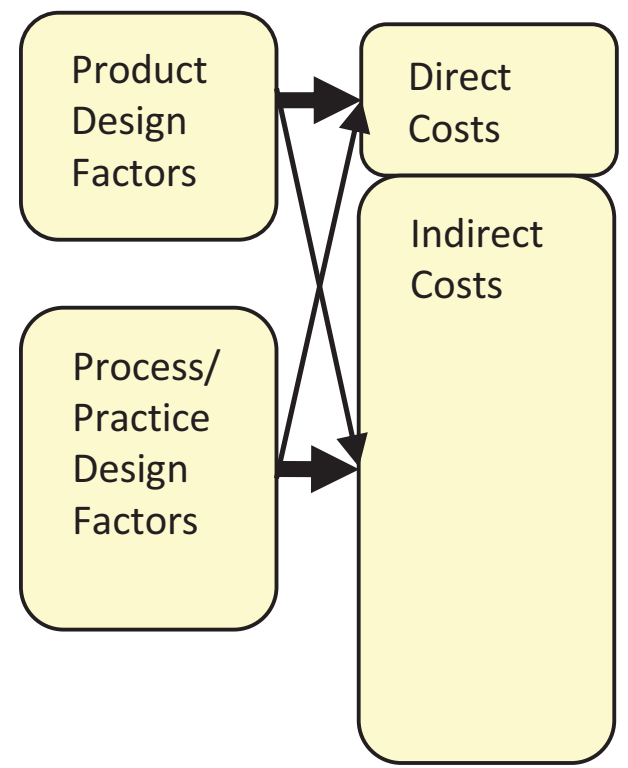

Weak link Strong link

Methodology / model used in current models and analysis
Figure 8: Technical product design factors ("what"; such as a number of parts, or different fluids, or the type of fluid, and reliability, etc.) distinguished from non-technical process factors ("how"; such as development practices, the flow of information, manufacturing steps, etc.)

Needs:

- Acceptance: Project/program cost data as a necessity, not a cost itself, not a luxury

- Insights, traceability

- Understanding and separating what comprises costs from what causes costs (not the same thing)

- Getting into the less tangible, less "technology" alluring indirect

- Technology that focuses on direct processes/responsiveness, productivity, in all phases from manufacturing to ops and launch; not just in flight 
An Analysis and Review of Measures and Relationships in Space Transportation Affordability

- What is needed is and ability to discriminate:

- cost-per-pound of launch vehicle payload capability

- cost-per-pound of payload delivered

- Specifically, need cost and productivity information:

- Annual Production and Supply Chain Costs as a function of Unit Production Rate

- Annual Operations Costs as a function of delivery (flight) rate 
An Analysis and Review of Measures and Relationships in Space Transportation Affordability

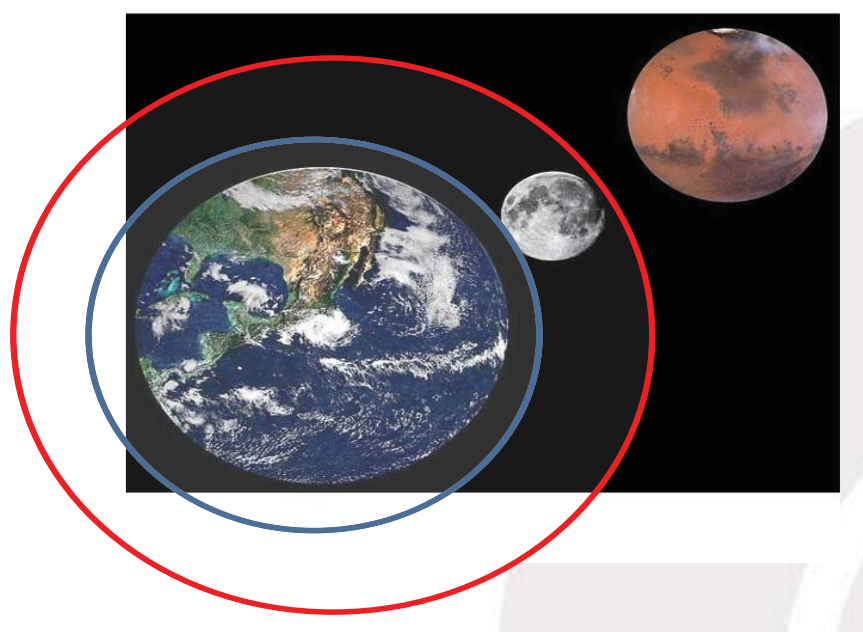

? Time

? Flight Rate \& Productivity
Figure 9: If some fixed resource is dedicated to launch, and a business or government enterprise also wants to go further, for longer, then launcher/transportation affordability must significantly improve.

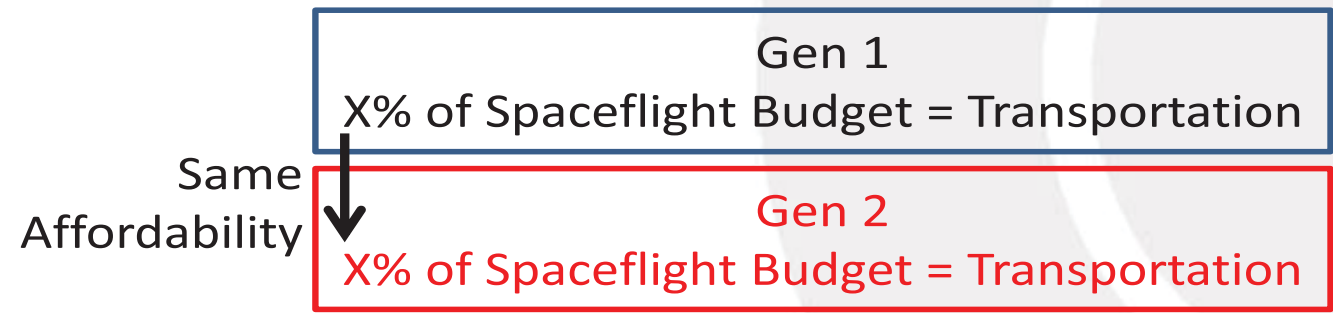

- Always the same few variables: resources, time, flight rate

- Stretching time/schedule, or dropping flight rate only gets so much

- Assuming budgets as in last 40 years, affordability, productivity and competitiveness must improve to allow space development and exploration 


\section{OMIn}

The World's Forum for Aerospace Leadership 